\title{
A Study of the Elements in Sooty Mould Phytopathology by Physical Techniques.
}

P.H.A. Aragão", N.M. Suguihiro*, S.B. Dos Santos*, M. Estevam*, E.C.S. Da Costa $^{*}$ E. Di Mauro ${ }^{*}$, M.A.C. Melo ${ }^{* *}$, A.P. Junior ${ }^{* *}$ and V.F. Nascimento Filho ${ }^{* * *}$

*Departamento de Física, CCE, Universidade Estadual de Londrina, Campus Universitário, 86051-990 Londrina, PR, Brasil. (phtd@tdkom.net).

** Departamento de Física, CCE, Universidade Estadual de Maringá, Maringá, PR, Brasil.

***Laboratório de Metodologia de Radioisótopos, CENA/USP, Piracicaba, SP, Brasil.

This work we applied the physical techniques of scanning electron microscopy (SEM) and microanalysis (EDS), energy dispersive X-ray fluorescence (EDXRF), electronic paramagnetic resonance (EPR) and Möessbauer spectroscopy to study the sooty mould. The measurements were realized with infected and non-infected leaves (olive, orange, lemon and coffee) found in the Mediterranean area, Sardegna (Italy) and Farm Scholl of Londrina State University, Londrina (Brazil). Results from the analysis showed a correlation between $\mathrm{Fe}$ and $\mathrm{Ca}$ in infected and non-infected leaves. More than 300 spectra from the most distinct plantation areas found analyzed. All of them presented the same $\mathrm{Fe}$ and $\mathrm{Ca}$ competitive pattern (fig. 1 and fig. 2). Several elements, at the macro (K and $\mathrm{Ca}$ ) and micro (Ti, Mn,Fe, $\mathrm{Ni}, \mathrm{Cu}, \mathrm{Zn})$ nutrients level were identified in the non-infected leaves spectra (Table 1). The elements $\mathrm{K}, \mathrm{Ca}, \mathrm{Ti}, \mathrm{Mn}, \mathrm{Fe}, \mathrm{Cu}$ and Zn were quantified by EDXRF. The high Fe concentration level observed by EDXRF and by EDS in sooty mould infected leaves made possible for the EPR and the Möessbauer spectroscopy to determine the $\mathrm{Fe}$ oxidation state and concluded that treat of organic is compound in the state $\mathrm{Fe}^{3+}$.

References:

[1] P.H.A.Aragão et al., J. Rad.and N.Chemistry, 249, (2001) 509.

[2] R. Cesareo, X-ray Physics, Rivista del Nuovo Cimento, Italy, 2000.

[3] T. Florkowski et al., J. A.R.and Isotopes, 28, (1977) 679.

[4] This research was supported by CAPES (PROCAD N ${ }^{\circ} 003 / 01-8$ and PET); CNPq (PIBIC/UEL); FAPESP and CPG/UEL/ ARAUCÁRIA FUNDATION. 


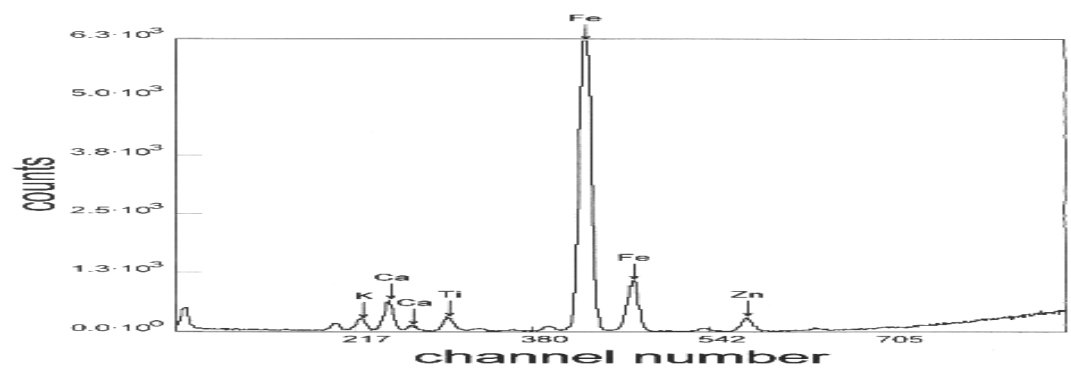

FIG. 1. Spectrum of EDS by SEM in coffee infected leaves.

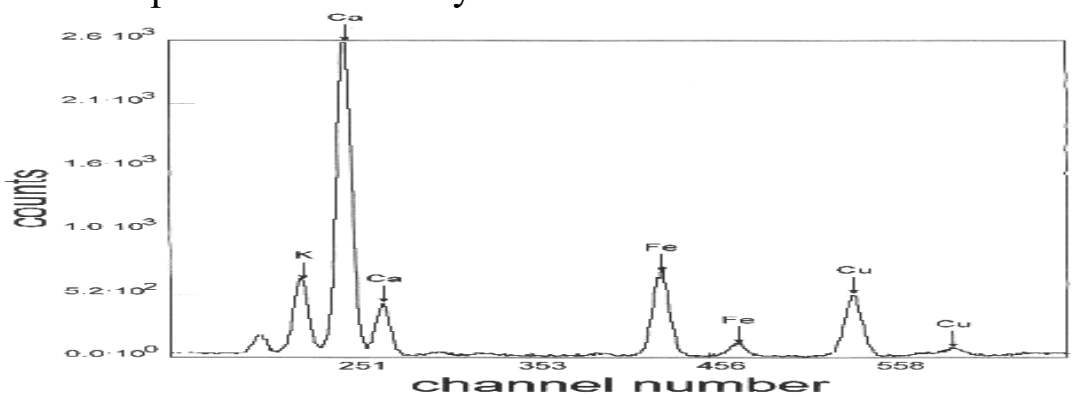

FIG. 2. Spectrum of EDS by SEM in coffee non-infected leaves.

\begin{tabular}{|c|c|c|}
\hline Elements & Non-infected & infected \\
\hline $\mathrm{K}-\mathrm{K}_{\alpha}$ & $3,444 \pm 66$ & $1,490 \pm 52$ \\
\hline $\mathrm{Ca}-\mathrm{K}_{\alpha}$ & $4,449 \pm 71$ & $3,632 \pm 67$ \\
\hline $\mathrm{Ti}-\mathrm{K}_{\alpha}$ & $70 \pm 22$ & $656 \pm 38$ \\
\hline $\mathrm{Mn}-\mathrm{K}_{\alpha}$ & $121 \pm 22$ & $298 \pm 29$ \\
\hline $\mathrm{Fe}-\mathrm{K}_{\alpha}$ & $575 \pm 31$ & $14,737 \pm 125$ \\
\hline $\mathrm{Ni}-\mathrm{K}_{\alpha}$ & - & $76 \pm 27$ \\
\hline $\mathrm{Cu}-\mathrm{K}_{\alpha}$ & $175 \pm 25$ & $652 \pm 35$ \\
\hline $\mathrm{Zn}-\mathrm{K}_{\alpha}$ & $308 \pm 33$ & $2,810 \pm 63$ \\
\hline
\end{tabular}

TABLE 1. Analysis in coffee leaves by EDXRF spectrum. 